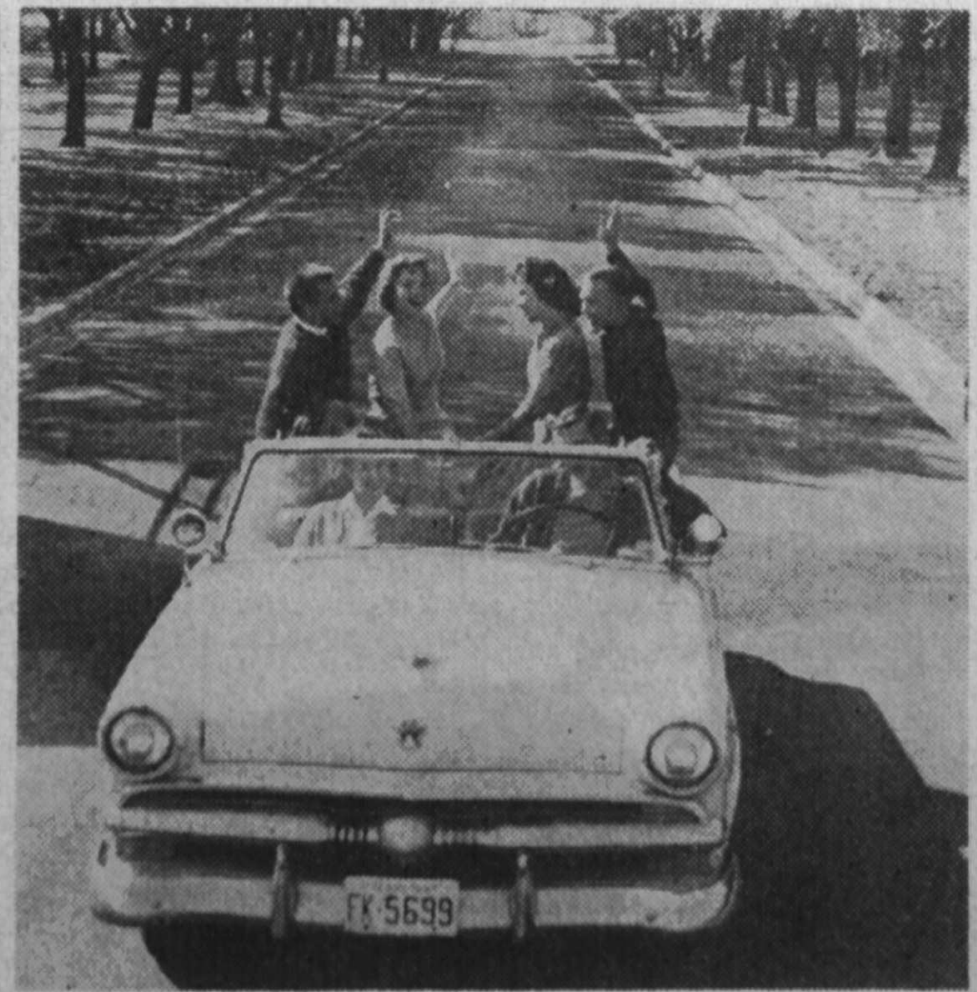

\title{
Parting Is Such Sweet Sorrow
}

It's good-bye to the campus for most students this weekend as they observe Thanksgiving holidays. For those who are not leaving, at least it will be a break from the grind for a while, anyway. 